\title{
Fitness evaluation of Encarsia sophia parasitizing Aleurocybotus indicus on two rice cultivars
}

\author{
Huizhong Sun $^{1}$ and Yueqin Song ${ }^{1 *}$ \\ ${ }^{1}$ Henan University of Science and Technology, College of Agriculture, Luoyang 471023, China. \\ *Corresponding author (songyueqin6@163.com).
}

Received: 18 September 2019; Accepted: 30 December 2019; doi:10.4067/S0718-58392020000200209

\begin{abstract}
Banker plant system has been widely used to control vegetable pests through the use of different combinations of host plant-alternative host natural enemy. In order to control the destructive pest Bemisia tabaci (Gennadius, 1889) (Hemiptera: Aleyrodidae) with banker plant system, estimating the reproductive potential of parasitoid Encarsia sophia (Girault \& Dodd, 1915) (Hymenoptera: Aphelinidae) parasitizing and feeding on alternate host rice whitefly Aleurocybotus indicus (Hymenoptera: Aphelinidae) is critically necessary. Two rice cultivars ('Changyou' and 'Jinjing') were used as banker plant. Our research showed that the longevity of E. sophia female adult in 'Changyou' treatment was significantly longer than that in 'Jinjing' treatment. The intrinsic rate of increase (r) and net reproductive rate $\left(\mathrm{R}_{0}\right)$ of $E$. sophia parasitizing A. indicus on 'Changyou' rice plant were $0.2295 \mathrm{~d}^{-1}$ and 34.6 eggs, respectively, and significantly greater than those on 'Jinjing' (0.0.2001 $\mathrm{d}^{-1}$ and 26.4 eggs) rice plant. Additionally, the net host feeding rate $\left(\mathrm{q}_{\mathrm{x}}\right)$ of E. sophia feeding on A. indicus in 'Changyou' (36.6 rice whitefly) treatment was significantly greater than that (23.7) in 'Jinjing' treatment. In conclusion, between two rice cultivars that were tested in this study, 'Changyou' rice plant could serve as a suitable banker plant for rearing E. sophia in biological control programs. The established banker plant system might provide growers with a new option for long-term control of $B$. tabaci in vegetable production.
\end{abstract}

Key words: Biological control, banker plant, Encarsia sophia, life table, rice whitefly, silver leaf whitefly.

\section{INTRODUCTION}

Banker plant system, i.e. open-rearing systems, takes the attention gradually due to gather the advantages of augmentative and conservation biological control (Frank, 2010). The typical banker plant system consists of three parts, including a non-crop banker plant, a non-pest herbivore, and natural enemies (Zheng et al., 2017). In this biological control strategy, the non-pest herbivore was used as an alternative host or prey for breeding parasitoid and predator (Xiao et al., 2011). Because the parasitoid at egg, larva, and pupa stage was in the body of alternate host, the effect of alternate host on the population fitness and control efficiency of parasitoid was great (Huang et al., 2011). Selecting a suitable alternate host was the critical step for establishing an efficient banker plant system.

Previous studies have shown that host plant species or cultivars affect the development time of parasitoids (Kalule and Wright, 2005; Lampert and Bowers, 2010). However, the effects of host plants on parasitoid development are probably not simply due to the differences in host plant resistance to their host. For example, Aphidius colemani (Viereck) developed significantly faster on the cabbage aphid, Brevicorvne brassicae (L.), reared on cabbage 'Ruby Ball' than on 'Minicole', although both cultivars are partially resistant to B. brassicae (Kalule and Wright, 2005). In contrast, development time of a polyphagous tachinid parasitoid of a lepidopteran, Compsilura concinnata Meigen, was shorter on the cabbage looper, Trichoplusia ni Hübner, fed on cucumber (a suitable host) than those fed on tomato (a less suitable host) (Caron et al., 2008). In the study of Pan et al. (2014), Aphidius gifuensis developed faster on aphids reared on the two susceptible 
cultivars, AK58 and Xinong979, than on the relatively resistant 'Xiaoyan22'. Some herbivore insects can sequester defensive compounds from the host plant and reduce their quality as parasitoid's hosts, and then negatively influence host acceptance and parasitoid development (Ode et al., 2004; Moreau et al., 2009; Ode and Crompton, 2012).

The silver leaf whitefly, Bemisia tabaci (Gennadius, 1889) (Hemiptera: Aleyrodidae) is one of the most devastating pests and plant virus vectors throughout the world (Rakha et al., 2017; Kaur et al., 2017). Its host range is wide, including vegetable, ornamental, and greenhouse crops (Roditakis et al., 2017). The application of insecticides is the primary whitefly control strategy on these crops (Basij et al., 2017; Rakha et al., 2017). Due to the critical concern about the abuse of pesticides, the interest in the biological control strategies increased gradually (Chen and Liu, 2011). Encarsia sophia (Girault \& Dodd, 1915) (Hymenoptera: Aphelinidae) has been used to control B. tabaci. However, the cost and control efficiency of augmentative biological control strategy with E. sophia were unfavorable (Xiao et al., 2011). To establish an efficient banker plant system consisting of E. sophia, it is necessary to evaluate the reproductive potential of E. sophia parasitizing alternate host.

Rice (Oryza sativa L.) is the host of the relatively host specific whitefly Aleurocybotus indicus (David \& Subramaniam, 1976) (Homoptera: Aleyrodidae), which could be parasitized by the parasitoid E. sophia. Furthermore, E. sophia proved strong capability of parasitism and feeding compared to other parasitoids. Therefore, the objective of this study was evaluating the reproductive potential of $E$. sophia parasitizing and feeding on alternate host $A$. indicus on rice plants for developing a successful banker plant system for controlling B. tabaci.

\section{MATERIALS AND METHODS}

\section{Insects and plants}

In 2018, the parasitoid Encarsia sophia was supplied by the college of Agricultural and Food Science, Zhejiang A\&F University, Lin'an City. This parasitoid was reared on rice (Oryza sativa L.) plants with alternate host Aleurocybotus indicus. The rice plants 'Changyou' and 'Jinjing' grown in plastic pots $(12 \mathrm{~cm}$-diameter) filled with a peat moss:perlite soil mix (3:1 ratio) were watered and fertilized as needed (Xu et al., 2019). Both parasitoids and its host $A$. indicus were enclosed in nylon net $(40 \mathrm{mesh})$ cages (dimensions: $60 \times 60 \times 60 \mathrm{~cm}$ ) and maintained in air-conditioned insectaries at $25 \pm 2{ }^{\circ} \mathrm{C}$ and $70 \pm 10 \% \mathrm{RH}$ with a photoperiod of $14: 10 \mathrm{~h}$.

\section{Life tables}

Approximately $20 \mathrm{~d}$ old rice plants $(\mathrm{n}=10)$ grown in plastic pots $(12 \mathrm{~cm}$-diameter) were used as the host plants for $A$. indicus. Aleurocybotus indicus adults $(\mathrm{n}=30)$ came from 'Changyou' and 'Jinjing' wheat (Triticum aestivum $\mathrm{L}$.) plants and were reared on the homologous rice plants. Aleurocybotus indicus and rice plants were enclosed in nylon net cages to allow for feeding and reproduction. Adults of A. indicus were removed $24 \mathrm{~h}$ later and the eggs were maintained on the rice plant until developing to fourth instar. The fourth instar nymph was used in the life table experiments.

Before the life table study, the parasitoids E. sophia were reared with A. indicus on 'Changyou' and 'Jinjing' rice plants, both of which served as the host plants for five generations. Ten mated $E$. sophia female adults emerged from $A$. indicus were introduced into the nylon net cages using an aspirator. After reproducing for $24 \mathrm{~h}$, the parasitoid adults were removed. The rice plants ('Changyou' and 'Jinjing') in the nylon net cages with parasitized and unparasitized A. indicus were maintained in an incubator at $25 \pm 0.5{ }^{\circ} \mathrm{C}, 70 \pm 10 \% \mathrm{RH}$ and a photoperiod of $14: 10 \mathrm{~h}$. A week later, the parasitized A. indicus developed as mummified. Not mummified A. indicus were removed with a hairbrush. Fifty mummies were randomly selected from each nylon net cage for use in the next step.

All mummies were inspected daily until the parasitoids emerged as adults or died. Emerged female and male E. sophia adults were paired. When the number of female adults was greater than males, other males were used to pair with the females. Each pair was supplied with 20 fourth instar A. indicus nymphs in a nylon net cage for $24 \mathrm{~h}$ of oviposition and feeding. The parasitoids were transferred daily to a new nylon net cage with 20 fourth instar $A$. indicus nymphs reared on the 'Changyou' and 'Jinjing' plants. This process was repeated until the E. sophia female died. A new male was provided if the male died before the female. After removing all parasitoids, rice plants with A. indicus were placed in growth separate chambers and checked daily. The development time, survival rate, longevity, parasitizing rate and host feeding rate of parasitoid were recorded on a daily basis. 


\section{Life table and host feeding analysis}

The raw data of development, survival rate, longevity, and female daily fecundity of E. sophia individuals were analyzed according to an age-stage, two-sex life table using the computer program TWOSEX-MSChart (Chi, 2019a). The agestage specific survival rate $\left(\mathrm{s}_{\mathrm{x} j}\right)$, age-specific survival rate $\left(\mathrm{l}_{\mathrm{x}}\right)$, age-stage specific fecundity $\left(\mathrm{f}_{\mathrm{x} j}\right)$, age-specific fecundity $\left(m_{x}\right)$, age-specific net fecundity $\left(l_{x} m_{x}\right)$, net reproductive rate $\left(R_{0}\right)$, intrinsic rate of increase $(r)$, finite rate of increase $(\lambda)$, mean generation time $(\mathrm{T})$, age-stage life expectancy $\left(\mathrm{e}_{\mathrm{x}}\right)$, and age-stage reproductive value $\left(\mathrm{v}_{\mathrm{x}}\right)$ were calculated based on Chi (2019a). In this study, $x$ is age and $j$ is stage.

Data on daily host feeding rates were analyzed using the CONSUME-MSChart program (Chi, 2019b). The host feeding rate was defined as the number of $A$.indicus killed by the parasitoids to obtain nutrition. The age-specific host feeding rate $\left(\mathrm{k}_{\mathrm{x}}\right)$, age-specific net host feeding rate $\left(\mathrm{q}_{\mathrm{x}}\right)$, cumulative host feeding rate $\left(\mathrm{C}_{\mathrm{x}}\right)$, finite host feeding rate $(\psi)$, and stable host feeding rate $(\omega)$ were calculated using $\mathrm{Chi}(2019)$ and Wang et al. (2016) methods. The net host feeding rate $\left(\mathrm{C}_{0}\right)$ was the total number of $A$. indicus killed by an average individual during its life span.

Bootstrap method was used to estimate the variance and standard error of the population parameters and host feeding rates (Polat-Akköprü et al., 2015). To reduce the variability of the estimates, we used 100000 bootstrap iterations according to Polat-Akköprü et al. (2015). The paired bootstrap test was used to detect significant differences between treatments.

\section{RESULTS}

\section{Development and fecundity}

Due to the variable developmental rate of E. sophia individuals, there was overlap among egg, larva+pupa and adult stages (Figure 1). The development duration of E. sophia is shown in Table 1. There was nonsignificant difference in the egg and Larva+pupa stages of E. sophia between 'Changyou' and 'Jinjing' treatments. The longevity of E. sophia parasitizing A. indicus on 'Changyou' (14.4 d) was significantly longer than that on 'Jinjing' (12.3 d).

Figure 1. Age-stage specific survival rate $\left(\mathrm{s}_{\mathrm{x} j}\right)$ of Encarsia sophia parasitizing Aleurocybotus indicus on 'Changyou' (A) and 'Jinjing' (B) rice plants.

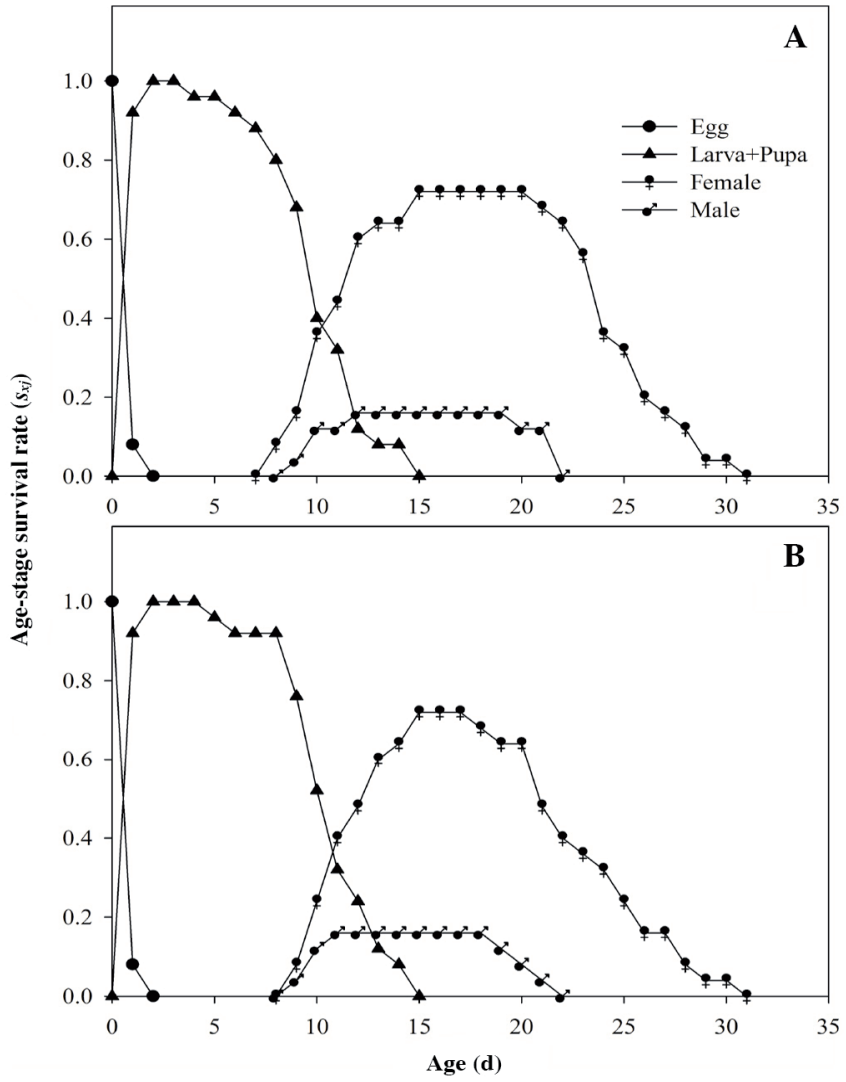


Table 1. Development and fecundity of Encarsia sophia parasitizing and feeding on Aleurocybotus indicus on 'Changyou' and 'Jinjing' rice plants.

\begin{tabular}{|c|c|c|c|c|}
\hline \multirow[b]{2}{*}{ Stage } & \multicolumn{2}{|c|}{ Changyou } & \multicolumn{2}{|r|}{ Jinjing } \\
\hline & $\mathrm{n}$ & Mean \pm SE & $\mathrm{n}$ & Mean \pm SE \\
\hline Egg, d & 80 & $1.1 \pm 0.3 \mathrm{a}$ & 80 & $1.1 \pm 0.3 \mathrm{a}$ \\
\hline Larva+Pupa, d & 80 & $9.7 \pm 0.4 \mathrm{a}$ & 80 & $10.3 \pm 0.4 \mathrm{a}$ \\
\hline Female adult, d & 53 & $14.4 \pm 0.5 \mathrm{a}$ & 50 & $12.3 \pm 0.5 b$ \\
\hline Male adult, d & 21 & $11.3 \pm 0.5 \mathrm{a}$ & 23 & $10.5 \pm 0.7 \mathrm{a}$ \\
\hline Oviposition, d & 53 & $13.4 \pm 0.5 \mathrm{a}$ & 50 & $11.6 \pm 0.5 b$ \\
\hline Fecundity, egg & 53 & $48.1 \pm 1.7 \mathrm{a}$ & 50 & $36.7 \pm 2.3 \mathrm{a}$ \\
\hline
\end{tabular}

Different letters in the same row mean significant difference (paired bootstrap test, $P<0.05)$.

\section{Fecundity}

The oviposition time of E. sophia in 'Changyou' (13.4 d) treatment was also significantly longer than that on 'Jinjing' (11.6 d) treatment. The mean number of egg produced by E. sophia female adult parasitizing A. indicus on 'Changyou' was 48.1 eggs, and significantly more than that on 'Jinjing' (36.7 eggs) (Table 1).

The number of eggs produced by E. sophia individuals at age $\mathrm{x}$ and stage $\mathrm{j}$ is shown in Figure 2 . The curve $\mathrm{f}_{\mathrm{x} 3}$ showed age-stage specific fecundity and represented females in the third life stage. The peak age-stage specific fecundity $\left(\mathrm{f}_{\times 3}\right)$, age-specific fecundity $\left(\mathrm{m}_{\mathrm{x}}\right)$, and age-specific fecundity $\left(\mathrm{l}_{\mathrm{x}} \mathrm{m}_{\mathrm{x}}\right)$ of $E$. sophia parasitizing A. indicus on 'Changyou' rice plant were $5.4,4.0$, and 3.5 eggs at $13^{\text {th }}$ day, respectively, and were the maximum values of $\mathrm{f}_{x}, \mathrm{~m}_{\mathrm{x}}$, and $\mathrm{l}_{\mathrm{x}} \mathrm{m}_{\mathrm{x}}$ in ' Jinjing' treatment was $3.9,3.2$ and 2.8 eggs at $16^{\text {th }} \mathrm{d}$, respectively.

Figure 2. Age-specific survival rate $\left(\mathrm{l}_{\mathrm{x}}\right)$, age-stage specific fecundity $\left(\mathrm{f}_{\mathrm{x} 3}\right)$, age-specific fecundity $\left(\mathrm{m}_{\mathrm{x}}\right)$, and age-specific net fecundity $\left(\mathrm{l}_{\mathrm{x}} \mathrm{m}_{\mathrm{x}}\right)$ of Encarsia sophia parasitizing Aleurocybotus indicus on 'Changyou' (A) and 'Jinjing' (B) rice plants.

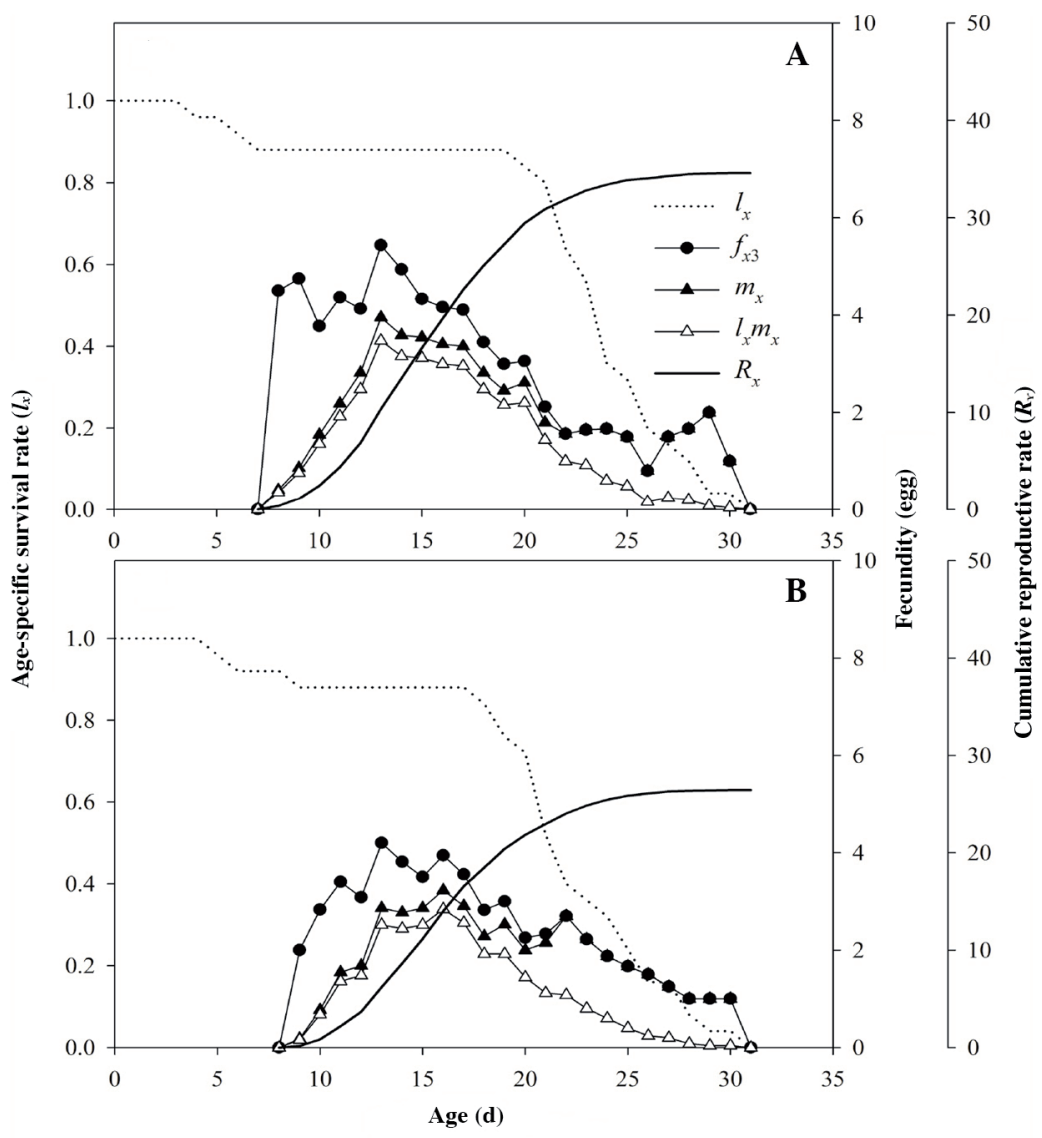




\section{Life expectancy $\left(\mathbf{e}_{\mathrm{x}}\right)$ and reproductive values $\left(\mathrm{v}_{\mathrm{x}}\right)$}

The value of age-stage life expectancy $\left(\mathrm{e}_{\mathrm{x} j}\right.$ ) was the remaining longevity that individual at age $\mathrm{x}$ and stage $\mathrm{j}$ could live (Figure 3). For example, the $\mathrm{e}_{\mathrm{x} j}$ of a newborn egg in 'Changyou' and 'Jinjing' treatments were 22.4, and $21.3 \mathrm{~d}$, respectively. The peak value of $\mathrm{e}_{\mathrm{xj}}$ for $E$. sophia females parasitizing A. indicus on 'Changyou' rice plant $(17.3 \mathrm{~d})$ was longer than that on 'Jinjing' rice plant (14.9 d). For male adult, the peak values of $e_{x j}$ in 'Changyou' and 'Jinjing' treatments were 12.5, and $11.5 \mathrm{~d}$, respectively.

The reproductive value $\left(\mathrm{v}_{\mathrm{xj}}\right)$ showed the contribution of individuals at age $\mathrm{x}$ and stage $\mathrm{j}$ to the future population. The maximum $\mathrm{v}_{\mathrm{x} j}$ of E. sophia in 'Changyou' and 'Jinjing' treatments were 20.8 and 17.0 eggs at $8^{\text {th }}$ and $11^{\text {th }} \mathrm{d}$, respectively (Figure 4).

Figure 3. Age-stage life expectancy ( $\mathrm{e}_{\mathrm{xj}}$ ) of Encarsia sophia parasitizing Aleurocybotus indicus on 'Changyou' (A) and 'Jinjing' (B) rice plants.

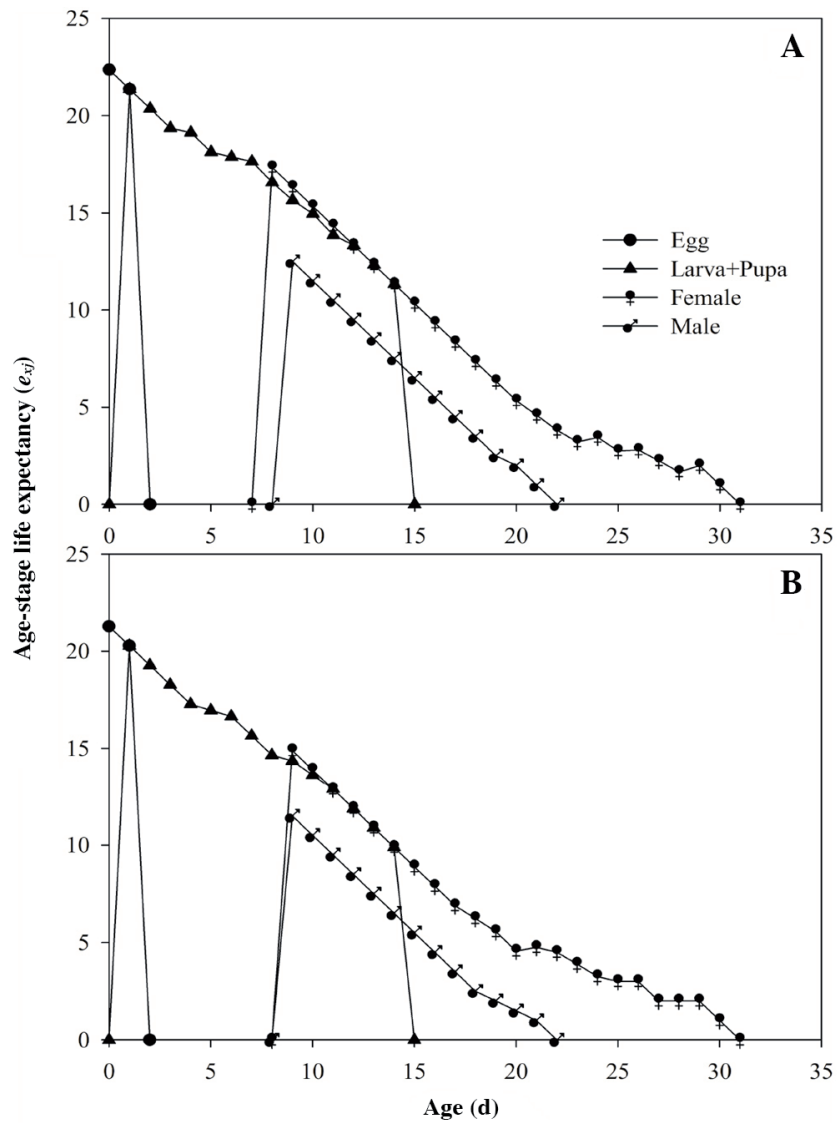

\section{Population parameters}

The population parameters of E. sophia are shown in Table 2. The intrinsic rate of increase (r) of E. sophia parasitizing A. indicus on 'Changyou' $\left(0.2295 \mathrm{~d}^{-1}\right)$ was significantly greater than that on 'Jinjing' $\left(0.2001 \mathrm{~d}^{-1}\right)$. The finite rate of increase $(\lambda)$ showed the similar phenomenon. The net reproductive rate $\left(\mathrm{R}_{0}\right)$ of E. sophia parasitizing A. indicus on 'Changyou' and 'Jinjing' were 34.6 and 26.4 eggs, respectively, and the $\mathrm{R}_{0}$ in 'Changyou' treatment was significantly greater than that in 'Jinjing' treatment. 
Figure 4. Age-stage reproductive value ( $\mathbf{v}_{\mathrm{xj}}$ ) of Encarsia sophia parasitizing Aleurocybotus indicus on 'Changyou' (A) and 'Jinjing' (B) rice plants.

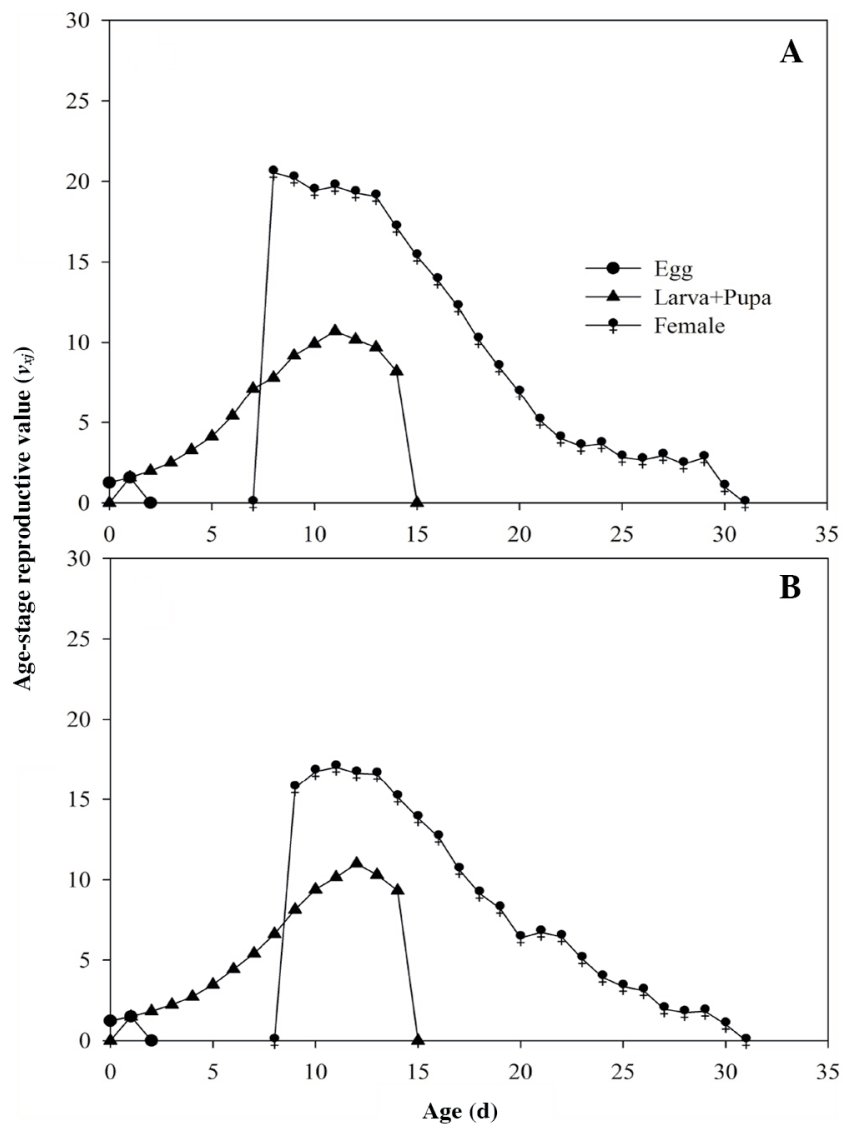

Table 2. Population parameters of Encarsia sophia parasitizing Aleurocybotus indicus on 'Changyou' and 'Jinjing' rice plants.

\begin{tabular}{lcc}
\hline Parameters & Changyou & Jinjing \\
\hline Intrinsic rate of increase $(\mathrm{r}), \mathrm{d}^{-1}$ & $0.2295 \pm 0.0115 \mathrm{a}$ & $0.2001 \pm 0.0102 \mathrm{~b}$ \\
Finite rate of increase $(\lambda), \mathrm{d}^{-1}$ & $1.2581 \pm 0.0145 \mathrm{a}$ & $1.2223 \pm 0.0124 \mathrm{~b}$ \\
Net reproductive rate $\left(\mathrm{R}_{0}\right)$, egg & $34.6 \pm 4.5 \mathrm{a}$ & $26.4 \pm 3.7 \mathrm{~b}$ \\
Mean generation time $(\mathrm{T}), \mathrm{d}$ & $15.4 \pm 0.5 \mathrm{a}$ & $16.3 \pm 0.5 \mathrm{a}$ \\
Net host feeding rate $\left(\mathrm{C}_{0}\right)$ & $36.6 \pm 4.8 \mathrm{a}$ & $23.7 \pm 3.3 \mathrm{~b}$ \\
Stable host feeding rate $(\omega)$ & $0.2660 \pm 0.0407 \mathrm{a}$ & $0.2035 \pm 0.0276 \mathrm{a}$ \\
Finite host feeding rate $(\psi)$ & $0.3346 \pm 0.0549 \mathrm{a}$ & $0.2487 \pm 0.0360 \mathrm{a}$ \\
\hline
\end{tabular}

Different letters in the same row mean significant difference (paired bootstrap test, $P<0.05)$. 


\section{Host feeding}

The host feeding rates of E. sophia are plotted in Figure 5. Because E. sophia could not feed on A. indicus at egg and larva+pupa stages, these stages formed gaps in the host feeding rate from egg to adult emergence. Both the age-specific host feeding rate $\left(\mathrm{k}_{\mathrm{x}}\right)$ and the age-specific net host feeding rate $\left(\mathrm{q}_{\mathrm{x}}\right)$ of E. sophia feeding on A. indicus on 'Changyou' and 'Jinjing' rice plants showed roughly periodic peaks during all adult stage. The peak value of $\mathrm{k}_{\mathrm{x}}$ in 'Changyou' treatment (3.7 eggs at $16^{\text {th }}$ day) was higher than that in 'Jinjing' ( 2.8 eggs at $15^{\text {th }}$ day) treatment. In addition, the maximum value of $\mathrm{q}_{\mathrm{x}}$ in 'Changyou' and 'Jinjing' treatments were 3.2 and 2.4 eggs, respectively, and the former is greater than the latter.

Figure 5. Age-specific host feeding rate $\left(k_{x}\right)$, age-specific net host feeding rate $\left(q_{x}\right)$, and cumulative host feeding rate $\left(C_{x}\right)$ of Encarsia sophia feeding on Aleurocybotus indicus on 'Changyou' (A) and 'Jinjing' (B) rice plants.

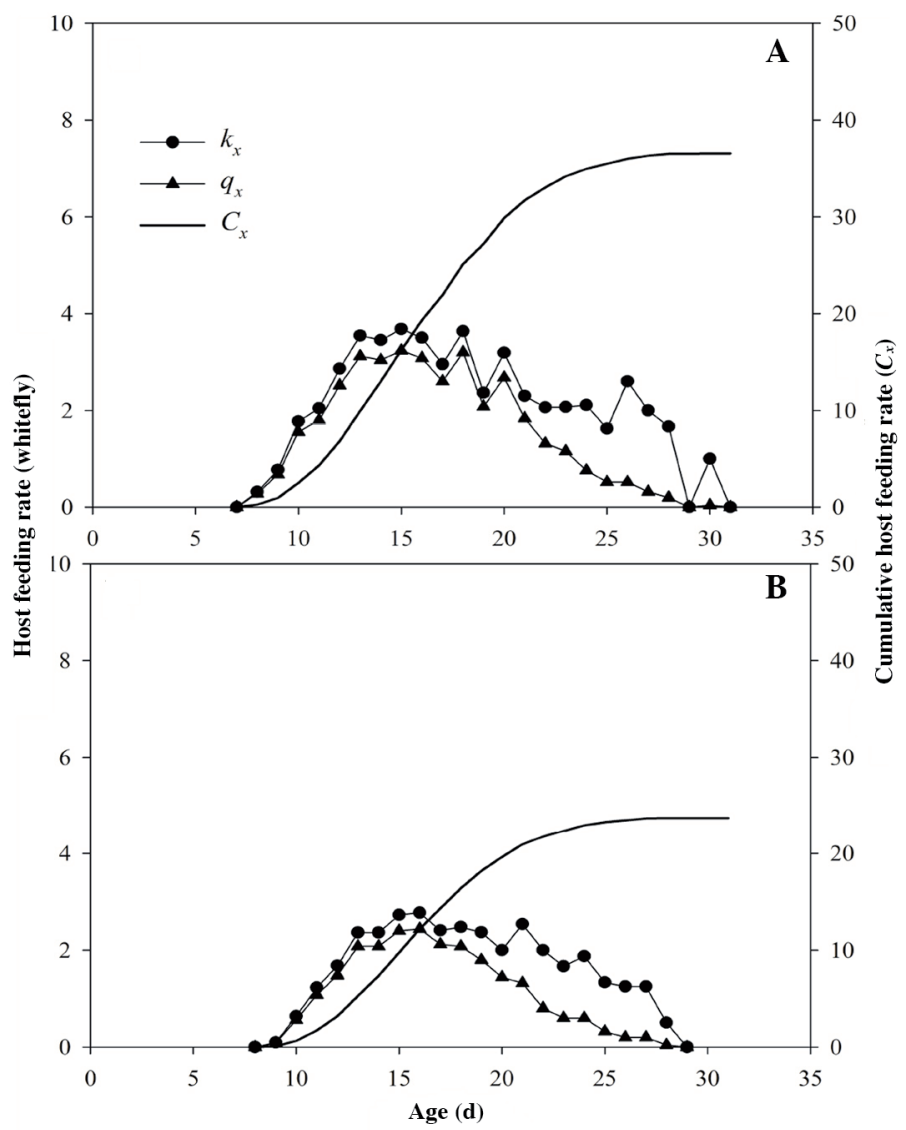

The cumulative net host feeding rates are shown in Table $2\left(\mathrm{C}_{\mathrm{x}}\right)$ and Figure $3\left(\mathrm{C}_{0}\right)$. The cumulative host feeding rate $\left(\mathrm{C}_{\mathrm{x}}\right)$ of E. sophia from birthday $(0 \mathrm{~d})$ was defined as the net host feeding rate $\left(\mathrm{C}_{0}\right)$. The $\mathrm{C}_{0}$ of E. sophia in 'Changyou' treatment was 36.6 eggs, and was significantly greater than that in 'Jinjing' (23.7 eggs) treatment. The stable host feeding rate $(\omega)$ and finite host feeding rate $(\psi)$ of E. sophia feeding on A. indicus on 'Changyou' $(0.2660$ and 0.3346$)$ were greater than on 'Jinjing' (0.2035 and 0.2487$)$, respectively. 


\section{DISCUSSION}

Results of this study indicated that the longevity and oviposition days of E. sophia parasitizing A. indicus on 'Changyou' rice plant were significantly longer than those on 'Jinjing' rice plant. In addition, the intrinsic rate of increase (r) of $E$. sophia in 'Changyou' treatment was significantly greater than that in 'Jinjing' treatment. The net reproductive rate $\left(\mathrm{R}_{0}\right)$ and net host feeding rate $\left(\mathrm{C}_{0}\right)$ also showed the similar phenomenon.

We found that E. sophia female adult lived longer when feeding on A. indicus on 'Changyou' rice plant, which suggested that the longevity of E. sophia female adult might be indirectly affected by host plant. In a previous study of Zhou et al. (2010), longevity of E. sophia female adult feeding on B. tabaci on tomato (Lycopersicon esculentum Mill., 'Pen Zhai Hong') was 12.8 d, which was different from our research. Both of those study suggested that the alternate host and host plant could affect the longevity of parasitoid, further affect the oviposition days. Different host plants have the potential to affect parasitoid development and performance by supplying hosts that differ in their nutritional value (Sarfraz et al., 2009; Lampert and Bowers, 2010). Besides, many insects have the ability to sequester defensive compounds from their host plants. These compounds can confer protection against attack by parasitoids and directly affect parasitoid survival and growth (Lampert and Bowers, 2010; Stoepler et al., 2011). The effect of the nutrition and defensive compounds of banker plant on the longevity of E. sophia should be researched in future.

The age-stage life expectancy $\left(\mathrm{e}_{\mathrm{xj}}\right)$ and reproductive value $\left(\mathrm{v}_{\mathrm{x}}\right)$ could be used to estimate the population dynamics. With the help of age-stage life expectancy $\left(\mathrm{e}_{\mathrm{x} j}\right)$, we can truly infer the reminding longevity of $E$. sophia at any age, which was beneficial to arrange the production plan. The reproductive value $\left(\mathrm{v}_{\mathrm{x} j}\right)$ showed the reproductive potential of $E$. sophia at age $\mathrm{x}$, which could be used to evaluate the control potential of $E$. sophia individuals at any time.

The net reproductive rate $\left(\mathrm{R}_{0}\right)$ of E. sophia in 'Changyou' (34.6 eggs) treatment was significantly greater than that in 'Jinjing' (26.4 eggs) treatment, which was less than that in the research of Zhang et al. (2016). The intrinsic rate of increase (r) of E. sophia parasitizing A. indicus on 'Changyou' was also significantly greater than that on 'Jinjing', which suggested that the 'Changyou' rice plant might be a more suitable banker plant for reproducing $E$. sophia efficiently. In a similar report of Zhang et al. (2016), the intrinsic rate of increase (r) of E. sophia feeding on B. tabaci on tomato ('Rui Qi First') was $0.2544 \mathrm{~d}^{-1}$, which was also different from the intrinsic rate of increase (r) of E. sophia in our study. In a previous study, a greater proportion of $B$. tabaci were parasitized by E. transvena Timberlake on tomato than on tobacco and eggplant. Rate of parasitism on tomato was 25.19 and on tobacco was 24.70 in greenhouse (Pillai et al., 2014). Both of these researches indicated that the effect of host plant on the parasitoid might be great. In addition, Giron et al. (2004) found that the increase in the fecundity of Eupelmus vuilletti is mainly determined by the amount of lipids obtained whereas the lifespan extension is mainly determined by carbohydrates. Therefore, the difference in the fecundity of $E$. sophia on two rice cultivars might be due to their nutrition. The amount of protein and carbohydrates in host and host plant should be study in future.

In the tritrophic interaction, the plant secondary metabolite was delivered from host plant to parasitoid along with nutrition. Many researches have indicated that host plants have direct or indirect effects on natural enemies of herbivore insects, especially for endoparasitoids (Sarfraz et al., 2009). The difference in plant secondary compound of 'Changyou' and 'Jinjing' might be the major reason influencing the suitability of E. sophia. In addition, in a successful parasitism behavior, there were four steps: (a) host habitat location, (b) host location, (c) host acceptance, and (d) host suitability, and the host plant is important for host location (Vinson, 1976). The physical characteristics of host plant might influence the efficiency of searching host for natural enemies, and further affect the population fitness of parasitoid. Therefore, the different performance of E. sophia in the fecundity may be affected by the host plants on which the host whitefly were reared.

\section{CONCLUSIONS}

The increasing population potential (intrinsic rate of increase and net reproductive rate) of Encarsia sophia parasitizing Aleurocybotus indicus on 'Changyou' rice plant was significantly greater than that on 'Jinjing' rice plant, which suggested that 'Changyou' might be the more suitable for establishing an efficiently banker plant system. 


\section{ACKNOWLEDGEMENTS}

This research was funded by the Natural Science Foundation of Henan Province of China (182300410024) and the National Natural Science Fund of China (31701788).

\section{REFERENCES}

Basij, M., Talebi, K., Ghadamyari, M., Hosseininaveh, V., and Salami, S.A. 2017. Status of resistance of Bemisia tabaci (Hemiptera: Aleyrodidae) to neonicotinoids in Iran and detoxification by cytochrome P450-dependent monooxygenases. Neotropical Entomology 46:115-124.

Caron, V., Myers, J., and Gillespie, D. 2008. Fitness-related traits in a parasitoid fly are mediated by effects of plants on its host. Journal of Applied Entomology 132:663-667.

Chen, L., and Liu, T.X. 2011. Fitness of Encarsia sophia (Hymenoptera: Aphelinidae) parasitizing Trialeurodes vaporariorum and Bemisia tabaci (Hemiptera: Aleyrodidae). Insect Science 18:84-91.

Chi, H. 2019a. TWOSEX-MSChart, a computer program for the age-stage, two-sex life table analysis. Available at http://140.120.197.173/Ecology/Download/TWOSEX-MSChart.rar (version 2019.12.09).

Chi, H. 2019b. CONSUME-MSChart, a computer program for consumption rate analysis based on the age-stage, two-sex life table. Available at http://140.120.197.173/Ecology/Download/CONSUME-MSChart.rar (version 2019.11.24).

Frank, S.D. 2010. Biological control of arthropod pests using banker plant systems: Past progress and future directions. Biological Control 52:8-16.

Giron, D., Pincebourde, S., and Casas, J. 2004. Lifetime gains of host-feeding in a synovigenic parasitic wasp. Physiological Entomology 29:436-442.

Huang, N., Enkegaard, A., Osborne, L.S., Ramakers, P.M.J., Messelink, G.J., Pijnakker, J., et al. 2011. The banker plant method in biological control. Critical Reviews in Plant Sciences 30:259-278.

Kalule, T., and Wright, D. 2005. Effect of cultivars with varying levels of resistance to aphids on development time, sex ratio, size and longevity of the parasitoid Aphidius colemani. BioControl 50:235-246.

Kaur, N., Chen, W., Zheng, Y., Hasegawa, D.K., Ling, K.S., Fei, Z.J., et al. 2017. Transcriptome analysis of the whitefly, Bemisia tabaci MEAM1 during feeding on tomato infected with the crinivirus, Tomato chlorosis virus, identifies a temporal shift in gene expression and differential regulation of novel orphan genes. BMC Genomics 18:370.

Lampert, E.C., and Bowers, M.D. 2010. Host plant species affects the quality of the generalist Trichoplusia ni as a host for the polyembryonic parasitoid Copidosoma floridanum. Entomologia Experimentalis et Applicata 134:287-295.

Moreau, J., Richard, A., Benrey, B., and Thiéry, D. 2009. Host plant cultivar of the grapevine moth Lobesia botrana affects the life history traits of an egg parasitoid. Biological Control 50:117-122.

Polat-Akköprü, E., Athhan, R., Okut, H., and Chi, H. 2015. Demographic assessment of plant cultivar resistance to insect pests: a case study of the dusky-veined walnut aphid (Hemiptera: Callaphididae) on five walnut cultivars. Journal of Economic Entomology 108:378-387.

Ode, P.J., Berenbaum, M.R., Zangerl, A.R., and Hardy, I.C. 2004. Host plant, host plant chemistry and the polyembryonic parasitoid Copidosoma sosares: indirect effects in a tritrophic interaction. Oikos 104:388-400.

Ode, P., and Crompton, D. 2012. Compatibility of aphid resistance in soybean and biological control by the parasitoid Aphidius colemani (Hymenoptera: Braconidae). Biological Control 64:255-262.

Pan, M.Z., Cao H.H., and Liu T.X. 2014. Effects of winter wheat cultivars on the life history traits and olfactory response of Aphidius gifuensis. BioControl 59:539-546.

Pillai, G.K., Ganga Visalakshy, P.N., Krishnamoorthy, A., and Mani, M. 2014. Evaluation of the indigenous parasitoid Encarsia transvena (Hymenoptera: Aphelinidae) for biological control of the whitefly Bemisia tabaci (Hemiptera: Aleyrodidae) in greenhouses in India. Biocontrol Science and Technology 24:325-335.

Polat-Akköprü, E., Athhan, R., Okut, H., and Chi, H. 2015. Demographic assessment of plant cultivar resistance to insect pests: a case study of the dusky-veined walnut aphid (Hemiptera: Callaphididae) on five walnut cultivars. Journal of Economic Entomology 108:378-387.

Rakha, M., Hanson, P., and Ramasamy, S. 2017. Identification of resistance to Bemisia tabaci Genn. in closely related wild relatives of cultivated tomato based on trichome type analysis and choice and no-choice assays. Genetic Resources \& Crop Evolution 64:247-260.

Roditakis, E., Stavrakaki, M., Grispou, M., Achimastou, A., Van Waetermeulen, X., Nauen, R., et al. 2017. Flupyradifurone effectively manages whitefly Bemisia tabaci MED (Hemiptera: Aleyrodidae) and tomato yellow leaf curl virus in tomato. Pest Management Science 73:1574-1584.

Sarfraz, M., Dosdall, L., and Keddie, B. 2009. Host plant nutritional quality affects the performance of the parasitoid Diadegma insulare. Biological Control 51:34-41. 
Stoepler, T.M., Lill, J.T., and Murphy, S.M. 2011. Cascading effects of host size and host plant species on parasitoid resource allocation. Ecological Entomology 36:724-735.

Vinson, S.B. 1976. Host selection by insect parasitoids. Annual Review of Entomology 21:109-133.

Wang, S.Y., Chi, H., and Liu, T.X. 2016. Demography and parasitic effectiveness of Aphelinus asychis reared from Sitobion avenae as a biological control agent of Myzus persicae reared on chili pepper and cabbage. Biological Control 92:111-119.

Xiao, Y., Chen, J., Cantliffe, D., Xiao, Y.F., Chen, J.J., Cantliffe, D., et al. 2011. Establishment of papaya banker plant system for parasitoid, Encarsia sophia (Hymenoptera: Aphilidae) against Bemisia tabaci (Hemiptera: Aleyrodidae) in greenhouse tomato production. Biological Control 58:239-247.

Xu, G.W., Song, K.J., Lu, D.K., Wang, H.Z., and Chen, M.C. 2019. Influence of water management and nitrogen application on rice root and shoot traits. Agronomy Journal 111:2232-2244.

Zhang, C.R., Lü, B., Wang, Z., Zang, L.S., and Ruan, C.C. 2016. Analyses of parasitism potential of parasitoid wasps Encarsia sophia and Encarsia formosa on the greenhouse whitefly Trialeurodes vaporariorum. Journal of Plant Protection 43:129-134.

Zheng, X., Lu, Y., Zhu, P., Zhang, F., Tian, J., Xu, H., et al. 2017. Use of banker plant system for sustainable management of the most important insect pest in rice fields in China. Scientific Reports 7:45581.

Zhou, C.Q., Li, Y., Liu, T.X., Zhang, F., and Luo, C. 2010. Development and morphology of female immature of Encarsia sophia and their longevity and fecundity. Chinese Journal of Biological Control 26:113-118. 